\title{
High temperature adduct formation of trimethylgallium and ammonia
}

\author{
A. Thon and T. F. Kuech \\ Department of Chemical Engineering, University of Wisconsin, 1415 Engineering Drive, Madison, \\ Wisconsin 53706
}

(Received 17 January 1996; accepted for publication 26 April 1996)

\begin{abstract}
High temperature gas phase reactions between trimethylgallium (TMG) and ammonia were studied by means of in situ mass spectroscopy in an isothermal flow tube reactor. The temperature, pressure, and reaction time were chosen to emulate the gas phase environment typical of the metal-organic vapor phase epitaxy (MOVPE) of GaN. The main gas phase species is $\left[\left(\mathrm{CH}_{3}\right)_{2} \mathrm{Ga}_{\mathrm{NH}} \mathrm{NH}_{x}\right.$, where most probably $x=3$, resulting from the very fast adduct formation followed by elimination of methane. The further gas phase decomposition of this species proceeds through the stepwise elimination of methane. These studies indicate that little TMG exists within the growth ambient under most MOVPE growth conditions. The further gas phase reaction of $\left[\left(\mathrm{CH}_{3}\right)_{2} \mathrm{Ga}: \mathrm{NH}_{2}\right]_{x}$ may be responsible for the strong dependence of the MOVPE GaN growth rate and uniformity commonly observed. (c) 1996 American Institute of Physics. [S0003-6951(96)00527-X]
\end{abstract}

The metal-organic vapor phase epitaxy (MOVPE) has emerged as the current growth technique of choice for the growth of $\mathrm{GaN}$ for device structures. ${ }^{1}$ Recent successes in the MOVPE formation of commercially viable blue and green light emitters have resulted in an increased activity in understanding the growth process and its relationship to the physical properties of these materials. While MOVPE can produce these materials, the growth of device-quality $\mathrm{GaN}$ is complicated by the severe and complicated gas phase interactions, that occur between trimethylgallium [(TMG or $\left(\mathrm{CH}_{3}\right)_{3} \mathrm{Ga}$ ] and ammonia, $\mathrm{NH}_{3}$ which are the commonly used growth precursors. ${ }^{2}$ These gas phase interactions have been suggested to lead to gas phase depletion of the growth nutrients leading to a degradation in the growth uniformity and efficiency. ${ }^{3}$ A primary gas phase reaction is the strong adduct forming reaction between $\mathrm{NH}_{3}$ and $\mathrm{TMG}^{4-7}$ In this present study, we have directly monitored this gas phase reaction in order to better understand its impact on the growth process and system design under those conditions particularly important for MOVPE growth. The species responsible for growth are the direct result of these gas phase reactions.

The gas phase reactions of both TMG and $\mathrm{NH}_{3}$, individually, are relatively understood at this point. The pyrolysis of TMG has been widely studied. ${ }^{8-12}$ The initial step in the TMG decomposition is generally agreed to be the removal of the first methyl radical, resulting in methane as the main product released in the decomposition. In the stepwise first order decomposition of TMG, an apparent activation energy has been measured for the first and second methyl groups, of $58-60 \mathrm{kcal} / \mathrm{mol}$ (Refs. 8 and 10) and $35.4 \mathrm{kcal} /$ mol, respectively. ${ }^{8}$ Under similar thermal conditions ammonia is quite stable. The gas phase decomposition of $\mathrm{NH}_{3}$ occurs only at very high temperatures. ${ }^{13}$ The heterogeneous decomposition of $\mathrm{NH}_{3}$ may, therefore, be essential to $\mathrm{GaN}$ growth.

The gas phase reaction between $\left(\mathrm{CH}_{3}\right)_{3} \mathrm{Ga}$ and $\mathrm{NH}_{3}$ is less understood, particularly at elevated temperatures characteristic of MOVPE growth environments. TMG and $\mathrm{NH}_{3}$, like other III-V Lewis acid-Lewis base combinations, ${ }^{4}$ can form intermediate coordination compounds at low temperatures. ${ }^{5-7,14,15}$ The adduct compound trimethylgalliummonamine (TMG: $\mathrm{NH}_{3}$ ) forms between the electron ac- ceptor (Lewis acid) TMG and the electron donor (Lewis base) ammonia, as indicated in Eq. (1):

$$
\left(\mathrm{CH}_{3}\right)_{3} \mathrm{Ga}+\mathrm{NH}_{3} \Leftrightarrow\left(\mathrm{CH}_{3}\right)_{3} \mathrm{Ga}: \mathrm{NH}_{3} \text {. }
$$

The structure, thermodynamic properties, and reaction mechanisms of this adduct at low temperatures have been intensely studied..$^{5-7,14}$ It has a moderate melting point of $31^{\circ} \mathrm{C}$ and has a low vapor pressure of about 1 Torr at room temperature. ${ }^{15}$ The estimated and measured strength of this $\mathrm{Ga}-\mathrm{N}$ coordination bond are $21.1 \mathrm{kcal} / \mathrm{mol}$ and $18.5 \mathrm{kcal} /$ mol, respectively. ${ }^{3}$ Recent studies show that at $\sim 90{ }^{\circ} \mathrm{C}$ this adduct reacts to form a six member ring, Cyclo(trimmidohexamethyltrigallium $)\left[\left(\mathrm{CH}_{3}\right)_{2} \mathrm{Ga}: \mathrm{NH}_{2}\right]_{3}$, with the release of one methane molecule per $\mathrm{Ga}$ atom. ${ }^{15,16}$ This process can be described by the reaction

$$
3\left[\left(\mathrm{CH}_{3}\right)_{3} \mathrm{Ga}: \mathrm{NH}_{3}\right] \Rightarrow\left[\left(\mathrm{CH}_{3}\right)_{2} \mathrm{Ga}: \mathrm{NH}_{2}\right]_{3}+3 \mathrm{CH}_{4} \text {. }
$$

As indicated by Eqs. (3) and (4), this overall reaction is suggested to proceed in two steps. The first step is the methane-elimination reaction with the subsequent release of a single $\mathrm{CH}_{4}$. The second step is the oligomerization of this specie into the three member ring.

$$
\begin{aligned}
& \left(\mathrm{CH}_{3}\right)_{3} \mathrm{Ga}: \mathrm{NH}_{3} \Rightarrow\left(\mathrm{CH}_{3}\right)_{2} \mathrm{Ga}: \mathrm{NH}_{2}+\mathrm{CH}_{4}, \\
& 3\left[\left(\mathrm{CH}_{3}\right)_{2} \mathrm{Ga}: \mathrm{NH}_{2}\right] \Rightarrow\left[\left(\mathrm{CH}_{3}\right)_{2} \mathrm{Ga}: \mathrm{NH}_{2}\right]_{3} .
\end{aligned}
$$

The estimated energy required for the elimination reaction is $49 \mathrm{kcal} / \mathrm{mol}^{3}$

As stated above, the gas phase chemistry relevant to MOVPE growth of GaN, however, takes place at temperatures that are significantly higher, ranging from a few hundred degrees $\mathrm{C}$ to near $1100{ }^{\circ} \mathrm{C}$. The actual significance of adduct formation and decomposition at these higher process temperatures has not been determined despite the potential impact that these reactions can have on the growth rate and uniformity.

We studied the high temperature gas phase reactions between TMG and $\mathrm{NH}_{3}$ by means of in situ mass spectroscopy within a flow tube or model isothermal reactor. The gas phase decomposition of TMG, $\mathrm{NH}_{3}$, and the combined TMG- $\mathrm{NH}_{3}\left(\mathrm{ND}_{3}\right)$ systems in $\mathrm{H}_{2}$ and $\mathrm{D}_{2}$ were studied over the temperature range $100-800{ }^{\circ} \mathrm{C}$. The room temperature 


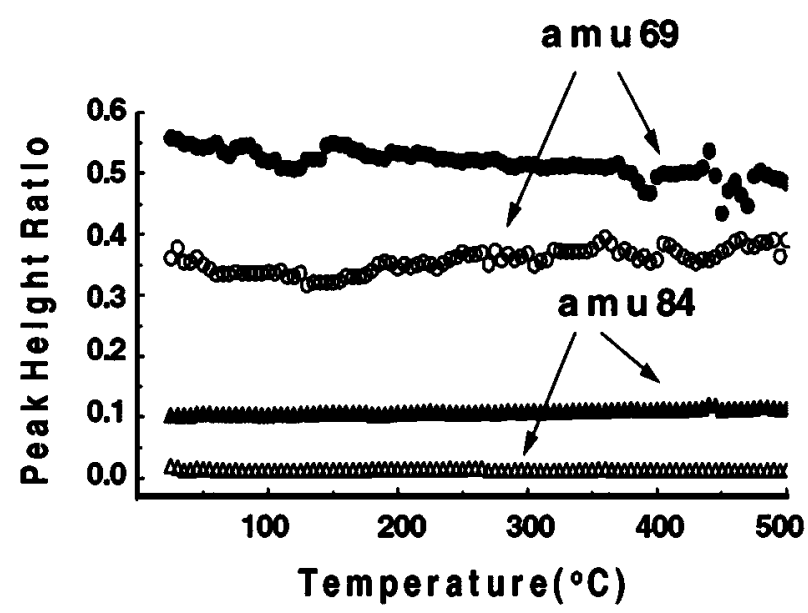

FIG. 1. The temperature dependence of the TMG-derived mass spectroscopy peaks are tracked for both the $\mathrm{TMG} / \mathrm{H}_{2}$ (filled symbols) and TMG/ $\mathrm{NH}_{3} / \mathrm{H}_{2}$ (empty symbols) systems. This figure shows the normalized intensity of mass 69 and mass 84 to that of mass 99 . The shift in the ratio of the $69 / 99$ and 84/99 mass peaks between these two chemical systems indicates the formation of the gas phase adduct.

formation of the liquid TMG- $\mathrm{NH}_{3}$ adduct complicates the experimental determination of the high temperature behavior of these compounds. In order to circumvent any premature partial decomposition of the TMG prior to mixing and react-
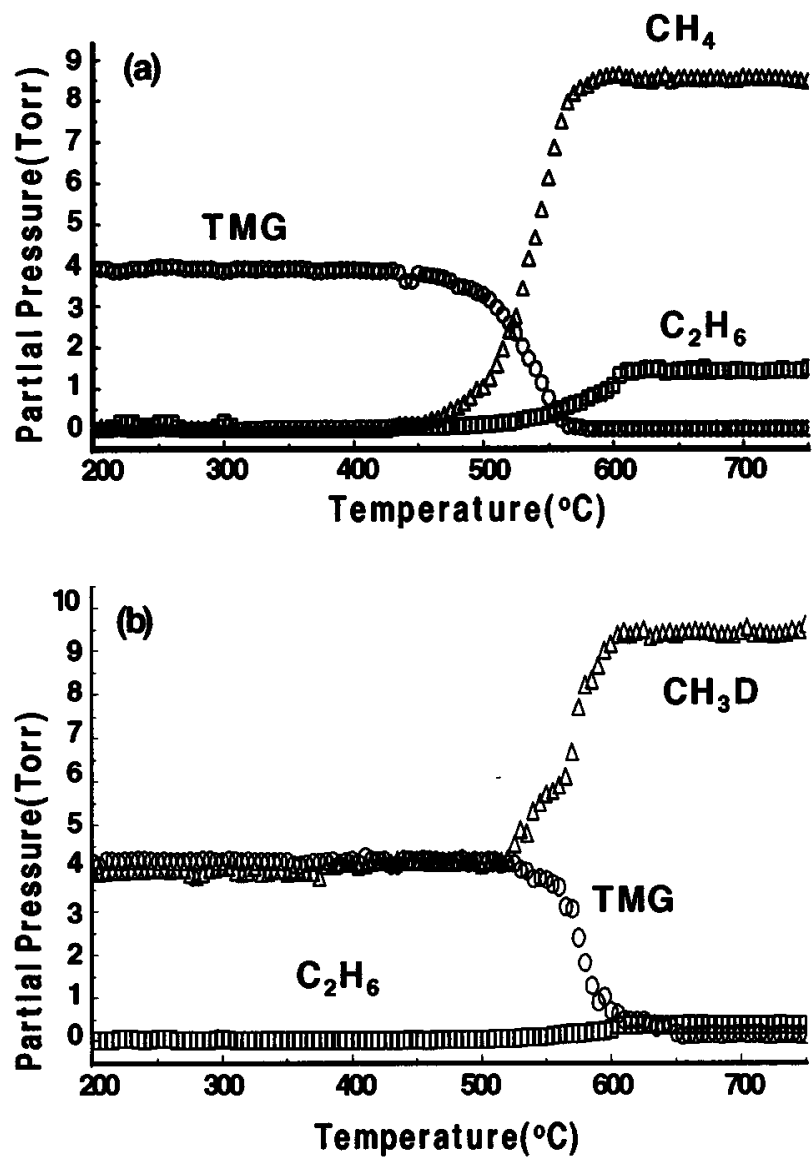

FIG. 2. The temperature dependence of decomposition within the TMG/ $\mathrm{H}_{2}$ (a) and TMG/ $\mathrm{H}_{2} / \mathrm{NH}_{3}$ (b) systems. Immediate reaction between TMG and $\mathrm{ND}_{3}$ results in the elimination of a single $\mathrm{CH}_{3} \mathrm{D}$ is observed at higher temperature. Complete decomposition of TMG within the $\mathrm{TMG} / \mathrm{H}_{2} / \mathrm{ND}_{3}$ system is achieved at about $50{ }^{\circ} \mathrm{C}$ higher than without $\mathrm{TMG} / \mathrm{H}_{2}$. ing with the $\mathrm{NH}_{3}$, a two temperature zone reaction furnace was used. ${ }^{17}$ To avoid any unintentional adduct formation at room temperature, the two primary reactants, TMG and $\mathrm{NH}_{3}$, were allowed to mix only in this first hot zone of the reactor. The initial gas phase reaction, forming the volatile adduct, occurs at temperatures $<200{ }^{\circ} \mathrm{C}$ within this first zone. This adduct and its initial reaction products are transported to the second temperature zone where it undergoes decomposition over a temperature range up to $800^{\circ} \mathrm{C}$. The reacted stream was sampled from within the hot isothermal regions of the reactor through an initial $75 \mu \mathrm{m}$ diameter nozzle, and was further expanded in molecular flow and measured by a residual gas analyzer. The inlet gas stream contained $0.5 \%$ of Ar during all experiments. Gas expansion artifacts in the mass spectroscopy data were eliminated in the data analysis through the normalization of all signals to the Ar peak intensity. Separate temperature scans were obtained using $\mathrm{CH}_{4}, \mathrm{TMG}$, and $\mathrm{NH}_{3}$ alone, which served to provide an accurate calibration for the determination of the partial pressure of the reaction products in later measurements.

The gas phase homolysis of TMG in $\mathrm{H}_{2}$ and $\mathrm{D}_{2}$ was carried out and compared to previous measurements of TMG decomposition in $\mathrm{H}_{2}$ (Ref. 10) as a reference. The TMG mole fraction in the inlet of the reactor was $0.015-0.05$. Measurements of the copyrolysis of TMG and ammonia, at high temperatures, utilized both $\mathrm{NH}_{3}$ as well as in deuterated ammonia, $\mathrm{ND}_{3}$, in order to distinguish between possible reaction mechanisms. All experiments were done in a quartz flow tube reactor at a MOVPE pressure of 76 Torr. The adduct and related compounds do not have a unique set of peaks since the relatively high energy electron impact in the mass spectrometer immediately breaks the adduct $\mathrm{Ga}-\mathrm{N}$ bond. ${ }^{18,19}$ The peak at $m / e=69,84$, and 99 , characteristic of TMG decomposition, can also be indicative of the adducts $\left(\mathrm{CH}_{3}\right)_{3} \mathrm{Ga}: \mathrm{NH}_{3}$ and $\left(\mathrm{CH}_{3}\right)_{2} \mathrm{Ga}: \mathrm{NH}_{2}$.

The TMG decomposition in both $\mathrm{H}_{2}$ and $\mathrm{H}_{2} / \mathrm{NH}_{3}$ is presented in Fig. 2. Differences between the reaction in $\mathrm{H}_{2}$ and in $\mathrm{H}_{2} / \mathrm{NH}_{3}$ ambients were found in the ratio of the $m / e=69$ and 84 to that of $m / e=99$. Several features are indicated in Fig. 1. The shift in the peak height ratio between the TMG/ $\mathrm{H}_{2}$ and $\mathrm{TMG} / \mathrm{H}_{2} / \mathrm{NH}_{3}$ cases indicates that there is a gas phase reaction occurring, leading to a thermally stable product, presumably an adduct or adduct-reacted product, up to temperatures of $500{ }^{\circ} \mathrm{C}$. More importantly, there is little or no thermal decomposition indicated in the TMG-derived peaks in either the $\mathrm{H}_{2}$ or $\mathrm{H}_{2} / \mathrm{NH}_{3}$ ambients over this temperature range.

The temperature dependence of decomposition, within the TMG/ $\mathrm{H}_{2}$ and $\mathrm{TMG} / \mathrm{H}_{2} / \mathrm{NH}_{3}$ systems is presented in Fig. 2. Peaks at $m / e$ values of $16,17,30$, and 99 were monitored corresponding to molecular fragments of $\mathrm{CH}_{4}$, $\mathrm{CH}_{3} \mathrm{D}, \mathrm{C}_{2} \mathrm{H}_{6}$ and $\left(\mathrm{CH}_{3}\right)_{2} \mathrm{Ga}$. The decomposition of TMG in $\mathrm{H}_{2}$ follows trends previously reported with an apparent activation energy determined to be $400-500{ }^{\circ} \mathrm{C}$ to be $51.4 \pm 1.5$ $\mathrm{kcal} / \mathrm{mol}$ and a pre-exponential factor of $(8.4 \pm 0.76)$ $\times 10^{13} \mathrm{~s}^{-1}$. The principal reaction product is methane, $\mathrm{CH}_{4}$, with ethane, $\mathrm{C}_{2} \mathrm{H}_{6}$, being found at higher temperatures. The simple mass balance between the calibrated peak heights of all the carbon based peaks accounts for all of the initial carbon in the form of $\mathrm{CH}_{4}$ and $\mathrm{C}_{2} \mathrm{H}_{6}$. These results are in 
agreement with previous determinations of these pyrolysis reactions. $^{9-11}$

The decomposition of TMG in a feed composition of $60 \% \mathrm{H}_{2}, 35 \% \mathrm{ND}_{3}$ and 5\% TMG is also presented in Fig. 2. Several trends are readily noted. There is an immediate reaction between TMG and $\mathrm{ND}_{3}$ resulting in the elimination of a single $\mathrm{CH}_{3} \mathrm{D}$ molecule over the temperature range of $<200{ }^{\circ} \mathrm{C}-\sim 500{ }^{\circ} \mathrm{C}$. No further reaction, beyond this initial release of methane is noted until a temperature of $\sim 500{ }^{\circ} \mathrm{C}$. The decrease in the TMG (adduct)-derived peaks occurs at a temperature $\sim 50{ }^{\circ} \mathrm{C}$ higher than the $\mathrm{TMG} / \mathrm{H}_{2}$ mixture. The full decomposition results in the stepwise elimination of $\mathrm{CH}_{3} \mathrm{D}$. A total of three $\mathrm{CH}_{3} \mathrm{D} / \mathrm{TMG}$ molecules is formed at high temperatures. The overall apparent activation energy for the elimination of the last methyl group is $48.7 \pm 5.3 \mathrm{kcal} /$ mol, and the Arrhenius preexponential factor for this apparent first order process is $(4.3 \pm 0.41) \times 10^{13} \mathrm{~s}^{-1}$. The activation energy value is not only very close to that previously measured for the homolysis of TMG in $\mathrm{H}_{2}$, but also to the estimated required energy for methane elimination. ${ }^{3}$ Unlike TMG/ $\mathrm{H}_{2}$-based pyrolysis, we see very little $\mathrm{C}_{2} \mathrm{H}_{6}$ in the reaction products, even at high temperatures. Analogous experiments with $\mathrm{TMG} / \mathrm{NH}_{3} / \mathrm{D}_{2}$, run under identical conditions, failed to produce $\mathrm{CH}_{3} \mathrm{D}$, with only $\mathrm{CH}_{4}$ found in the product stream, similar to the TMG/AsH ${ }_{3}$ system. ${ }^{10}$ The homolysis of $\mathrm{CH}_{3}$ from the adduct species with a subsequent gas phase reaction with ammonia or hydrogen is not favored under our experimental conditions. Published rate constants for the gas phase reaction between methyl radicals, $\mathrm{CH}_{3}$, and either $\mathrm{NH}_{3}\left(\mathrm{ND}_{3}\right.$ in the present study) or $\mathrm{H}_{2}$ (Ref. 13) indicate that the gas phase formation of $\mathrm{CH}_{4}$ would be greater than, or comparable to the formation of $\mathrm{CH}_{3} \mathrm{D}$. Our experiments utilizing $\mathrm{ND}_{3}$ or $\mathrm{D}_{2}$ clearly indicate that all gas phase elimination of methane results from an intramolecular reaction or between the adduct-derived species and the excess ammonia. $^{20}$

While a complete reaction model for the high temperature decomposition of TMG: $\mathrm{ND}_{3}$ species cannot be obtained from these measurements, several conclusions can be made concerning the gas phase chemistry within a MOVPE growth environment, which can impact the design and growth processing conditions within this system. The formation of a gas phase adduct occurs at an extremely high rate when compared to $\sim 1$ s residence within our flow tube reactor. The gas phase species, presumably TMG: $\mathrm{ND}_{3}$ immediately selfeliminates a $\mathrm{CH}_{3} \mathrm{D}$ molecule at all temperatures monitored $\left(T>150{ }^{\circ} \mathrm{C}\right)$. The formation of the trimeric cyclic compound is predicted at low temperatures, however, our experimental system would not be capable of directly determining these high molecular weight species. This methane-eliminated species, $\left[\left(\mathrm{CH}_{3}\right)_{2} \mathrm{Ga}: \mathrm{ND}_{2}\right]_{x}$, is quite stable over the temperature range of $200-500{ }^{\circ} \mathrm{C}$. The shift in decomposition temperature, while possessing a similar activation energy to the $\mathrm{TMG} / \mathrm{H}_{2}$ pyrolysis, indicates that the preexponential factor in the kinetic rate expression for these reactions is lower relative to the $\mathrm{TMG} / \mathrm{H}_{2}$ case. Decomposition of $\left[\left(\mathrm{CH}_{3}\right)_{2} \mathrm{Ga}: \mathrm{ND}_{2}\right]_{x}$ finally proceeds until three $\mathrm{CH}_{3} \mathrm{D}$ molecules are removed per initial $\left(\mathrm{CH}_{3}\right)_{3} \mathrm{Ga}$ molecule. The final solid reaction product is unknown but is, however, presumed to be $\mathrm{Ga}$ or perhaps a $\mathrm{GaN} / \mathrm{Ga}$ mixture.
The implication of these studies for the design and operation of MOVPE reactors for GaN growth is several fold. In most or all MOVPE growth systems operating at conventional pressures (1-760 Torr), little, if any, $\left(\mathrm{CH}_{3}\right)_{3} \mathrm{Ga}$ exists in the growth environment. The rapid adduct formation reaction together with the immediate release of a single methane molecule implies that the dominant gas phase species within the reactor, at actual growth, is $\left[\left(\mathrm{CH}_{3}\right)_{2} \mathrm{Ga}: \mathrm{NH}_{2}\right]_{x}$, with most probably $x=3$. The further gas phase decomposition is due to the intramolecular elimination of $\mathrm{CH}_{4}$ from this species or reaction with the excess ammonia. These reactions can happen within the heated gas phase region above the MOVPE growth surface. The reactions of this species in the gas phase, through decomposition or further oligomerization, should be the principal mechanism by which the growth rate and growth rate uniformity is affected by the specific reactor design. Larger molecules, and eventually particles, will affect the growth rate through differences in the transport rate to the surface resulting from a difference in diffusion and thermal diffusion coefficients. The further decomposition of this species can be suppressed by an appropriate design of the MOVPE reactor. Several reactor schemes have been utilized to reduce "parasitic" gas phase reactions including separate injection of the growth species, split tube reactors, as well as the use of high gas velocities and low reactor pressures. Such system innovations can reduce the residence time or time at temperature in the gas phase of this specie, altering the eventual composition of the flux to the growth front.

The authors would like to acknowledge technical discussion with K. F. Jensen and S. Safvi. Financial support was provided by the ARPA-URI on Visible Light Emitters.

${ }^{1}$ I. Akasaki and H. Amano, J. Cryst. Growth 146, 455 (1995).

${ }^{2}$ A. C. Jones, S. A. Rushworth, and J. Auld, J. Cryst. Growth 146, 503 (1995).

${ }^{3}$ A. Zaouk, E. Salvetat, J. Sakaya, F. Maury, and G. Constant, J. Cryst. Growth 55, 135 (1981).

${ }^{4}$ R. H. Moss, J. Cryst. Growth 68, 78 (1984).

${ }^{5}$ D. Mazzarese, A. Tripathi, W. C. Conner, K. A. Jones, L. Calderon, and W. Eckart, J. Electron. Mater. 18, 369 (1989).

${ }^{6}$ B. S. Sywe, J. R. Schlup, and J. H. Edgar, Chem. Mater. 3, 737 (1991).

${ }^{7}$ M. J. Almond, C. E. Jenkins, D. A. Rice, and K. Hagen, J. Organomet. Chem. 439, 251 (1992).

${ }^{8}$ M. G. Jacko and J. W. Price, Can. J. Chem. 41, 1560 (1963).

${ }^{9}$ M. Yoshida, H. Watanabe, and F. Uesugi, J. Electrochem. Soc. 132, 677 (1985).

${ }^{10}$ S. P. DenBaars, B. Y. Maa, P. D. Dapkus, A. D. Danner, and H. C. Lee, J. Cryst. Growth 77, 188 (1986).

${ }^{11}$ C. A. Larsen, N. I. Buchan, S. H. Li, and G. B. Stringfellow, J. Cryst. Growth 102, 103 (1990).

${ }^{12}$ Q. Chen and P. D. Dapkus, J. Electrochem. Soc. 138, 2821 (1991).

${ }^{13}$ NIST Database 17: NIST Chemical Kinetics, U. S. Department of Commerce, National Institute of Standards and Technology (1994), see references therein.

${ }^{14}$ J. R. Durig, C. B. Bradley, and J. D. Odom, Inorg. Chem. 21, 1466 (1982).

${ }^{15}$ G. E. Coates, J. Chem. Soc. Part III, 2003 (1951).

${ }^{16}$ M. J. Almond, M. G. B. Drew, C. E. Jenkins, and D. A. Rice, J. Chem. Soc. , 5 (1992).

${ }^{17}$ A. Thon and T. F. Kuech (unpublished).

${ }^{18}$ T. L. Brown, Ann. (N.Y.) Acad. Sci. 136, 98 (1966).

${ }^{19}$ F. H. Field and J. L. Franklin, Electron Impact Phenomena and the Properties of Gaseous Ions (Academic, New York, 1957), pp. 53-79.

${ }^{20} \mathrm{~K}$. F. Jensen (private communication). 